\title{
Andragogi dan Teori Modal Sosial Untuk Pengembangan Sumber Daya Manusia Pada Kelompok Usaha Mandiri
}

\author{
Hanifah Fitria Azizah ', Entoh Tohani ${ }^{2}$ \\ Non-Formal Education Department, Yogyakarta State University \\ hanifahfitriaazizah567@gmail.com, tohani@uny.ac.id
}

\begin{abstract}
ABSTRAK
Artikel ini bertujuan untuk mendeskripsikan kontribusi Andragogi, pembelajaran mandiri, dan teori modal sosial dalam hubungan antara belajar orang dewasa dan pengembangan Sumber Daya Manusia (SDM) dalam sebuah kelompok usaha mandiri dan pelaksanaan proses kelompok usaha mandiri. Metode yang digunakan dalam penelitian ini adalah deskriptif kualitatif. Alat yang digunakan untuk menggumpulkan data yaitu observasi, wawancara dan dokumentasi. Adapun tehnik analisis data dilakukan dengan cara pengumpulan data, reduksi data, penyajian data dan penarikan kesimpulan. perspektif dari andragogi, pembelajaran individual, teori modal sosial sebagai kontribusi untuk diskusi pada hubungan antara teori belajar orang dewasa dan sumber daya manusia pada kelompok usaha mandiri. Pada teori andragogi dan modal sosial menawarkan kontribusi untuk mengubah tempat kerja tradisional ke dalam lingkungan belajar yang kondusif, menekankan pentingnya jaringan sosial, kemitraan, kolaborasi, interaksi, dan berbagi pengetahuan. Modal sosial menyediakan jaringan hubungan yang bermakna yang membantu mengintegrasikan ke dalam lingkungan kerja sehari-hari belajar. Hasil proses pengembangan sumber daya manusia pada kelompok usaha mandiri (KUM) yang diperoleh pertama perencanaan mulai dari penyadaran dan pembentukan organisasi. Kedua pelaksanaan dan pemanfaatan bahan baku lokal. Ketiga evaluasi. Keempat pendampingan untuk keberlanjutan inovasi program dan kendala yang dialami minimnya alat produksi yang bersumber dari keterbatasan modal dikarenakan keterbatasan dalam mengoptimalkan fungsi kemitraan.
\end{abstract}

Kata Kunci: Andragogi, Teori Modal Sosial, Kelompok Usaha Mandiri

ABSTRACT

This article aims to describe the contribution of Andragogy, independent learning, and social capital theory in the relationship between adult learning and the development of Human Resources (HR) in an independent business group and the implementation of an independent business group process. The method used in this study is descriptive qualitative. The tool used to collect data is observation, interviews and documentation. The data analysis technique is done by collecting data, reducing data, presenting data and drawing conclusions. perspectives from andragogy, individual learning, social capital theory as contributions to discussion on the relationship between adult learning theory and human resources in independent business groups. On andragogy theory and social capital offer contributions to transform traditional workplaces into conducive learning environments, emphasizing the importance of social networks, partnerships, collaboration, interaction and knowledge sharing. Social capital provides a network of meaningful relationships that help integrate into the daily work environment of learning. The results of the process of developing human resources in the independent business group (KUM) obtained first from the awareness and formation of the organization. Both the implementation and utilization of local raw materials. Third evaluation. The four facilitation for the sustainability of program innovations and the constraints experienced by the lack of production tools stemming from limited capital due to limitations in optimizing partnership functions.

Keywords: Andragogy, Social Capital Theory, Independent Business Groups 


\section{Diklus: Jurnal Pendidikan Luar Sekolah, 1(3), Maret 2019 - 38 Hanifah Fitria Azizah}

\section{PENDAHULUAN}

Konsep pengetahuan produktivitas menggambarkan proses yang memerlukan sinyal, mengidentifikasi, mengumpulkan, menyerap dan menafsirkan informasi yang relevan, menggunakan informasi ini untuk mengembangkan kemampuan baru dan menerapkan kemampuan ini tambahan untuk perbaikan dan inovasi radikal operasi prosedur, produk, dan layanan (Kessels, 2001). Bahkan, proses pengetahuan produktivitas adalah cara yang memfasilitasi individu belajar, tertanam dalam konteks sosial organisasi. Dalam konteks ini, pernyataan bahwa Andragogi, pembelajaran individual dan modal sosial membentuk perspektif dasar untuk pengembangan sumber daya manusia, dalam pengetahuan perekonomian yang didasarkan pada rantai berikut: sumber daya manusia memainkan peran penting dalam kelompok usaha mandiri, sebagai pengetahuan manusia adalah produsen utama. Dalam pengetahuan ekonomi, pertumbuhan didasarkan pada peningkatan dan inovasi proses kerja, produk, dan layanan dan adalah hasil dari pengetahuan produktivitas (Mulyono, 2015).

Proses belajar guna produktivitas pengetahuan ini akan membawa individu untuk mendapatkan gairah kerja, tanggung jawab, dan tantangan dalam berkarier yang akan bermuara pada keinginan individu untuk terus belajar dan belajar (Hayati, 2016). Berlandaskan hal tersebut, andragogi dan teori modal sosial perlu muncul dalam pengembangan SDM karena menawarkan asumsi-asumsi mengenai berharganya belajar mandiri, individu,dan jaringan sosial guna mencapai produktivitas pengetahuan bersama. Kemampuan kelompok usaha mandiri dalam pengembangan SDM baik dalam hal nilai, pengetahuan, dan inovasi menjadi lebih penting dibanding modal moneter, kerja fisik, maupun bahan baku. Untuk lebih memahami perkembangan ini, minat baru dalam belajar orang dewasa akan muncul, karena memiliki tradisi yang panjang dalam pembelajaran sosial, kritis, dan emansipatoris. Oleh karena itu, ketika sumber daya manusia untuk memainkan peran penting dalam pengetahuan ekonomi yang berkembang pada kelmpok usaha mandiri. Perlu untuk menemukan kembali Andragogi dan teori modal sosial sebagai bagian dari program kelompok usaha mandiri.

Fokus pengembangan SDM yang tadinya pada organisasi harus bergeser pada fokus individu untuk pembelajaran mandiri, tujuan, motivasi, dan kondisi yang dialaminya. Proses belajar ini terkait erat dengan refleksi diri, belajar dari kesalahan pribadi maupun orang lain, sikap kritis, umpan balik, kemampuan bereksperimen, dan berbagi pengetahuan bersama. Pembelajaran mandiri yang terjadi akan berpengaruh besar bagi terciptanya jaringan pengetahuan dalam lingkungan kerja. Lingkungan kerja harus mampu mendorong individu untuk terus belajar secara mandiri agar individu tersebut mampu membuat dan merenungi pilihannya sendiri serta membuat keputusan secara mandiri. Pembelajaran mandiri yang tercipta secara tidak langsung mengarah pada konsep pendidikan orang dewasa khususnya andragogi. Isu-isu kunci dalam andragogi seperti fokus pada pengalaman, kesadaran kritis dan pembebasan, berpikir kritias, reflektif, belajar sepanjang hayat, dan masih banyak lainnya memiliki kecenderungan yang berfokus pada individu (Knowles, 1970). Oleh karena itu, ketika penerapan asumsiasumsi andragogikal, peran pengembangan SDM harus mementingkan struktur sosial yang ada dalam lingkungan kerja sebagai fokus perhatian. Lebih lanjut dijelaskan bahwa teori modal sosial mungkin dapat menjawab dan melengkapi komponen andragogical yang selama ini berkembang.

Modal SDM sebagai sumber utama kinerja sebuah organisasi atau kelompok usaha mandiri dipandang tidak akan cukup. Perlu adanya modal sosial yang merupakan komponen penting dalam sebuah proses belajar mandiri dalam mencapai tujuannya (Abdul, 2017). Adanya modal sosial akan mendukung 


\section{Diklus: Jurnal Pendidikan Luar Sekolah, 1(3), Maret 2019 - 39 Hanifah Fitria Azizah}

pembelajaran individual kritis yang berdasarkan pada tanggung jawab bersama, integritas, kepercayaan, saling menghargai dan menghormati, serta kesadaran terhadap lingkungan sekitar. Modal sosial sendiri dapat diartikan sebagai sumber daya yang dapat diakses individu utuk melakukan tindakan; hasil dari interaksi yang dibangun dengan individu lain atau kelompok masyarakat. Modal sosial berbeda dengan modal fisik atau modal manusia. Individu memerlukan akses menuju jaringan sosial guna melakukan sesuatu dengan lebih baik. Oleh sebab itu lah, modal sosial merupakan sebuah investasi dalam membangun jaringan sosial yang berkaitan dengan waktu dan usaha.

Desa Sidoluhur adalah salah satu desa di Kecamatan Godean Yogyakarta yang memliki sumber daya manusia dan potensi wilayah yang berlimpah mulai dari daerah pertanian, dekat dengan pusat oleholeh, kelompok perikanan, kelompok peternak kambing, kelompok wanita tani dan pasar godean, tak kalah bagus dengan potensi alam yang mana terdapat pemandangan sawah yang indah, aliran Aliran selokan yang cukup deras desa sidoluhur dusun jowah terdapat aliran selokan yang cukup deras. Sehingga potensi yang satu ini dapat dimanfaatkan tenaganya dengan membuat Pembangkit Listrik Tenaga Mikrohidro (PLTMH), yaitu dengan membuat turbin air yang putarannya dapat dimanfaatkan untuk berbagai macam hal (sebagai pusat sentra perekonomian). Karena mereka memiliki pendidikan dan keterampilan yang memadai, justru seharunya mengantarkan mereka kepada suatu daya jual yang tinggi dan mengelola potensi lokal yang ada.

Berdasarkan uraian yang telah dikemukakan, penelitian ini berfokus pada kontribusi Andragogi, dan teori modal sosial dalam hubungan antara belajar orang dewasa dan pengembangan Sumber Daya Manusia (SDM) dalam sebuah kelompok usaha mandiri. Penelitian ini dilakukan di dusun jowah desa sidoluhur kecamatan godean.

\section{METODE}

Penelitian ini menggunakan metode penelitian kualitatif deskriptif. Penelitian kualitatif merupakan jenis penelitian yang digunakan untuk melihat dan menganalisa peristiwa dan gejala sosial yang terjadi secara lebih mendalam .Adapun teknik pengumpulan data melalui observasi, wawancara, dan dokumentasi. Teknik analisis data dengan cara pengumpulan data, reduksi data, penyajian data, penarikan kesimpulan. Tempat penelitian Desa Sidoluruh Godean Yogyakarta, dan waktu penelitian selama dua bulan.

\section{HASIL DAN PEMBAHASAN Hasil}

Andragogi dan teori modal sosial merupakan suatu pasangan tepat yang dapat menjadi dasar-dasar dalam pengembangan SDM. Kelompok usaha mandiri melalui lingkungan kerja yang terbentuk dipandang memiliki kunci dari sumber modal sosial yang menekankan pada pentingnya jaringan sosial, kemitraan, kolaborasi, interaksi, serta fasilitas berbagi pengetahuan. Modal sosial dibedakan menjadi 3 dimensi yang saling terkait yaitu: (1) Struktural, (2) Relasional, dan (3) Kognitif. Ketiga dimensi tersebut memiliki kaitan erat dengan pendidikan orang dewasa khususnya pendekatan andragogi. Sebagai contoh, dimensi relasional yang menfasilitasi terciptanya pengetahuan dan sharing pengetahuan itu sendiri, hal tersebut terjadi karena adanya akses menuju jaringan sosial untuk berkolaborasi antar sesama individu.

Modal sosial memegang peranan penting dalam proses belajar mandiri yang dilakukan oleh orang dewasa. Spesifik pada orang dewasa dalam sebuah usaha, perlu adanya penyiapan lingkungan kerja agar mampu menjadi lingkungan belajar yang kondusif bagi setiap anggota. Belajar mandiri yang dilakukan karyawan selaku orang dewasa terkadang dilakukan secara informal (tidak sadar, tidak direncanakan, dan alamiah) sehingga dapat terjadi dimanapun, kapanpun dan dimanapun. 


\section{Diklus: Jurnal Pendidikan Luar Sekolah, 1(3), Maret 2019 - 40 Hanifah Fitria Azizah}

proses belajar yang terjadi dalam sebuah kelompok usaha mandiri terjadi secara nonformal dan informal. Secara informal pembelajaran terjadi melalui banyak sumber misalnya interaksi dan komunikasi dengan anggota lain yang memiliki disiplin ilmu berbeda, menghadapi situasi baru, tuntutan pekerjaan, dan bahkan interaksi dengan pelanggan. Secara umum proses pembelajaran tersebut akan terjadi jika terdapat interaksi antara individu dengan individu atau kelompok. Oleh karena itu, modal sosial penting adanya guna mendukung proses belajar mandiri individu melalu interaksi yang dilakukannya.

\section{Proses Pelaksanaan Kelompok Usaha Mandiri}

Kelompok usaha mandiri di dusun jowah desa sidoluhur dibentuk pada tanggal 16 november 2018. yang membuka pengetahuan masyarakat untuk peduli betapa penting nya mengelola bahan mentah menjadi bahan jadi atau setengah jadi dengan memanfaatkan potensi lokal dan pendidikan. Dalam rangka mengembangkan kualitas kehidupan masyarakat dusun jowah, secara geografis wilayah memiliki potensi mulai dari daerah pertanian, dekat dengan pusat oleholeh, kelompok perikanan, kelompok peternak kambing, kelompok wanita tani dan pasar godean, tak kalah bagus dengan potensi alam yang mana terdapat pemandangan sawah yang indah, aliran Aliran selokan yang cukup deras desa sidoluhur dusun jowah terdapat aliran selokan yang cukup deras.

Desa Sidoluhur, Godean ,Yogyakarta secara geografis masyoritas penduduk nya agraris mata pencarian nya di bidang pertanian dan berdagang. Oleh karena itu hal ini sebagai masyarakat untuk menompang kehidupan ekonomi masyarakat, hal ini berpengaruh terhadap rendah nya kesadaran masyarakat akan pendidikan yang dilatarbelakangi karena kurang nya kesejahteraan masyarakat di bidang ekonomi. proses pelaksanaan nya di kolam ikan dusun jowah Desa sidoluhur, godean. tahapan kegiatan antarala lain yakni:

\section{a. Persiapan}

Hasil penelitian melalui observasi dan wawancara menunjukan bahwa .Kegiatan awal di lakukan dengan melakukan assesment kebutuhan serta melihat potensi lokal dari sumber daya alam nya maupun dari permintaan pasar. Penyadaran bahwa potensi lokal dari sumber daya alam nya bisa di kembangkan menjadi bahan jadi atau setengah jadi, dari pada hanya dijual bahan mentah, dengan cara bergabung ketika acara PKK ibu Desa sidoluhur. Langkah selanjutnya yakni sosialiasi program, membuat group via whatsapp. Menyiapkan pemateri sesuai dengan kebutuhan, menyipkan bahan praktek, menyiapkan alat dan bahan. Program tahapan awal yang di lakukan di balai Desa sidoluhur yang bertujuan untuk mensosialisasikan kepada masyarakat melalui ketua RT, pakdukuh, karang taruna selain itu tahap penyadaran atau sosialisasi di lakukan secara nonformal.

\section{b. Pelaksanaan}

Hasil penelitian menunjukan bahwa pelaksanaan pembentukan organisasi dan pelatihan pembuatan curry pufe dan risol frozen yang bahan utama nya dari ikan nila. Proses pelaksanaan nya berlangsung selama dua bulan dan dalam seminggu satu kali pertemuan, pelaksanaan pembelajaran lebih banyak pada teori sambil praktik dan evaluasi, yang menentukan waktu nya ibuibu Desa sidoluhur. Mulai perwakilan dari RT 1sampai dengan 6 dengan jumlah 20 orang. Bentuk proses pembelajaran nya lebih kepada teori dan action secara bersamaan atau langsung, sistem secara radikal. Jadi waktu prosesnya sangat fleksibel. Pendekatan yang digunakan lebih kepada partisipatif, yang mana didalam mengambil keputusan ibu-ibu di libatkan didalam nya, belajar sesuai pengalaman sebelumnya dan samapai pada hasil evaluasi tetap dilibatkan. Kemudian setelah 


\section{Diklus: Jurnal Pendidikan Luar Sekolah, 1(3), Maret 2019 - 41 Hanifah Fitria Azizah}

proses produksi selesai, lanjut pada tahap proses pengemasan produk dan pelabelan produk dan perhitungan food cost.

\section{Pelaksanaan Jejaring Internal Dan Eksternal}

Ada berberapa kerjasama internal : pokdarwis, kelompok wanita tani, kelompok peternakan, kelompok pemuda dan pemudi. Dan Eksternal : Dinas Kelautan dan Perikanan, Dinas Pariwisata dan Budaya.

\section{Pemanfaatan Bahan Baku Lokal.}

Hasil pengamatan peneliti menunjukan bahwa pemanfaatan bahan baku lokal ikan nila sudah diperoleh dari hasil tanaman lokal. Namun, bahan baku lokal belum mencukupi kebutuhan bahan baku ikan nila jika permintaan banyak sehingga bahan baku yang kurang. Berdasarkan data yang diperoleh dari wawancara, observasi, menunjukan bahwa saat ini bahan baku lokal hanya mampu mencukupi 60\% dari bahan yang dibutuhkan dalam produksi ikan nila jika permintaan banyak. Karena ada berberapa permintaan bahan mentah dari bererapa rumah makan.

\section{c. Evaluasi}

Pelaksanaan evaluasi dalam pembelajaran kelompok usaha mandiri dilakukan tahap demi tahap, dalam proses pembelajaran selalu ada evaluasi baik sedang berlangsung nya proses kegiatan dan di akhir proses pembelajaran. sementara dari hasil penelitian menunjukkan bahwa evaluasi yang dilakukan tidak di adakan nya evaluasi sumatif, akan tetapi yang dilakukan hanya evaluasi formatif

\section{Kendala Program}

Kendala yang dirasakan masyarakat dari program kelompok usaha mandiri pembuatan Risol Frozen dan Curry Puff di Desa Sidoluhur ini yaitu:

Kendala yang dihadapi yakni keterbatasan alat untuk memproduksi, di karenakan terbatas nya modal usaha, dan terbatas nya jam kerja karena sebagaian ibu-ibu ada yang bekerja sebagai petani dan pedagang. Oleh karena itu di perlukan nya kerja sama atau jaringan yang lebih luas lagi. Belum mengetahui pengukuran keberhasilan modal sosial dalam mempengaruhi pengembangan SDM sebuah kelompok usaha mandiri.

\subsection{Diskusi}

Andragogi dan teori modal sosial menawarkan perspektif gabungan dan menarik untuk pembelajaran dan perkembangan pengetahuan ekonomi. Mereka memberikan asumsi tentang fasilitasi belajar di tempat kerja, aspek motivasi kuat dan otonomi dalam pengembangan kompetensi, dan mengintegrasikan jaringan hubungan yang bermakna yang membantu pembelajaran dalam sosial konteks lingkungan kerja sehari-hari.

Di tingkat masyarakat atau masyarakat luas, praktisi sumber daya manusia dapat berkontribusi dengan cara berikut ke gedung modal sosial:

- meningkatkan tingkat pendidikan karyawan;

- membantu karyawan belajar dan mengembangkan sebagai orang;

- mempromosikan keterampilan jaringan sosial di karyawan;

- memajukan keragaman dan sadar lingkungan kebijakan, prinsip-prinsip demokrasi dan peluang sama.

Pada kelompok usaha mandiri melibatkan partisipatif aktif dari masyarakat, karena disini dihadapkan keterbatasan jaringan untuk pemasaran maka diperlukan ada nya modal sosial, dengan modal sossial kearifan loka dapat dibangun melalui partisipasi masyarakat untuk saling menghargai keberadaan nilainilai sosial budaya yang masih dibutuhkan untuk mengembangkan kehidupan masyarakat agar proaktif dalam merespon perubahan sosial. unsur-unsur yang dimaksud adalah partisipasi dalam jaringan sosial (participation and social network), (2) saling tukar kebaikan (reciprocity). (3) norma sosial (social norm), (4) nilai-nilai 


\section{Diklus: Jurnal Pendidikan Luar Sekolah, 1(3), Maret 2019 - 42 Hanifah Fitria Azizah}

sosial, dan (5) tindakan proaktif dengan begitu bisa mengerakkan eksistensi.

Andragogi didasarkan. Unsur-unsur penting adalah tanggung jawab fasilitator untuk membantu orang dewasa yang bergerak dari ketergantungan terhadap peningkatan diri dengan menggunakan pengalaman pribadi sebagai sumber daya yang kaya untuk belajar, terutama ketika berkaitan dengan tugas-tugas kehidupan nyata dan masalah pengembangan kompetensi dalam cara yang bermakna dan peran dominan Motivasi intrinsik dan harga diri.

Salah satu yang bisa dilakukan untuk mengembangkan dan menciptakan inovasi kelompok usaha mandiri ialah penting mempertimbangkan perspektif ekologi, perspektif keadilan sosial dan Hak Asasi Manusia, kemudian perspektif ekologi dan keadilan sosial menjadi visi dalam pengembangan masyarakat, menciptakan perubahan dari bawah atau button-up, dan melibatkan partisipasi aktif masyarakat dalam proses pemberdayaan masyarakat.

Berdasarkan hasil penelitian mengenai kontribusi andragogi dan teori modal sosial untuk pengembangan sumber daya manusia pada kelompok usaha mandiri yang telah diterangkan di atas maka peneliti dapat memberikan rekomendasi kepada pelaku kelompok usaha mandiri Desa sidoluhur terkait mengembangkan kelompok usaha mandiri dengan mengimplentasikan peningkatan kapasitas jejaring agar sumber daya seseorang dapat di hubungkan dengan melalui jaringan sosial. dan melakukan strategi deverifikasi konsenrasi strategi ini dilakukan dengan cara menambah produk dan farian rasa dari ikan nila itu sendiri.

\section{SIMPULAN}

Berdasarkan uraian hasil penelitian di atas maka dapat ditarik kesimpulan bahwa: Pertama tahap perencanaan yang di terapkan yaitu dengan assesment kebutuhan serta melihat potensi lokal dari sumber daya alam dan penyadaran dengan melakukan sosialisai dan ngobrol santai setelah acara arisan dan persiapan alat dan bahan selanjutnya menentukan pemateri. Kedua tapah pelaksanaan nya yaitu dengan, Proses pelaksanaan nya berlangsung selama dua bulan dan dalam seminggu satu kali pertemuan, pelaksanaan pembelajaran dengan cara pendekatan secara partisipatif, proses pembelajaran orang dewasa pada teori langsung praktik secara radikal. Pengemasan produk hingga penjualan baik kerjasama dari jejaring internal maupun eksternal. Ketiga evaluasi terkait sedang dalam proses pembelajaran dan setelah pembelajaran. Keempat kendala yang dihadapi yakni alat dikarenakan kapasitas jaringan sosial yang masih kurang dan sumber daya nya.

\section{Rekomendasi}

Rekomendasi untuk penelitian selanjutnya terkait mengenai kelompok usaha mandiri ialah penelitian pengembangan kelompok usaha mandiri pada jejaring .

\section{DAFTAR PUSTAKA}

Creswell, J.W. (1994). Research Design: Qualitative and Quantitative Approaches. SAGE Publications, Inc. Thousand Oaks.

Defourny, J., \& Nyssens, M. (2010).

Conceptions of social enterprise and social entrepreneurship in europe and the united states: convergences and divergences. Journal of Social Entrepreneuship, Vol 1(1);32.

Field, J. (2000). Lifelong learning and the new educational order. Stoke on Trent, UK: Trentham Books.

Freire, P. (1970). Pedagogy of the oppressed. New York: Herter and Herter.

Knowles, M. (1970) The Modern Practice of Adult Education: Andragogy versus Pedagogy, Associated Press, New York.

Knowles, Malcolm. (1977). The Adult Learner : A Neclected Selection. Houston:Gulf Publishing. 


\section{Diklus: Jurnal Pendidikan Luar Sekolah, 1(3), Maret 2019 - 43 \\ Hanifah Fitria Azizah}

Milles, M.B. and Huberman, M.A. (1984). Qualitative Data Analysis. London: Sage Publication

Muarifuddin, M., Mulyono, S. E., \& Malik, A. (2016). Analisis kebutuhan pengembangan desa wisata batik Kecamatan Lasem Kabupaten Rembang. Journal of Nonformal Education, 2(1), 57-70.

Mungmachon, M. R. (2012). Knowledge and local wisdom: Community treasure. International Journal of Humanities and Social Science, 2(13), 174-181

Nahapiet, J., \& Ghoshal, S. (1998). Social capital, intellectual capital, and the organizational advantage. Academy of Management Review, 23(2), 242-266.

Narayan, D. (2002). Empowerment and Poverty Reduction: A sourcebook. (D. Narayan, Ed.). Washington, DC: The World Bank. http://doi.org/10.1596/o-8213-51664 diakses 25 September 2018

Sudjana. 2005. Strategi Pembelajaran. Bandung: Falah Production

Tom Nesbit, Linda Leach \& Griff Foley .2004. Adult Education. Houston: Gulf Publishing.

Usman, Sunyoto. (200o). Pembangunan dan Pemberdayaan Masyarakat. Jakarta: Pustaka Pelajar. 